\title{
The Isolation and Mapping of Disease Resistance Gene Analogs in Maize
}

\author{
N. C. Collins, ${ }^{1}$ C. A. Webb, ${ }^{2}$ S. Seah, ${ }^{1,3}$ J. G. Ellis, ${ }^{1}$ S. H. Hulbert, ${ }^{2}$ and A. Pryor ${ }^{1}$ \\ 'Division of Plant Industry, Commonwealth Scientific and Industrial Research Organisation, Canberra, ACT \\ 2601, Australia; ${ }^{2}$ Department of Plant Pathology, Kansas State University, Manhattan 66506, U.S.A.; \\ ${ }^{3}$ Plant Sciences, The University of Western Australia, Nedlands, WA 6907, Australia \\ Accepted 24 June 1998.
}

\begin{abstract}
Many of the plant disease resistance genes that have been isolated encode proteins with a putative nucleotide binding site and leucine-rich repeats (NBS-LRR resistance genes). Oligonucleotide primers based on conserved motifs in and around the NBS of known NBS-LRR resistance proteins were used to amplify sequences from maize genomic DNA by polymerase chain reaction (PCR). Eleven classes of non-cross-hybridizing sequences were obtained that had predicted products with high levels of amino acid identity to NBS-LRR resistance proteins. These maize resistance gene analogs (RGAs) and one RGA clone obtained previously from wheat were used as probes to map 20 restriction fragment length polymorphism (RFLP) loci in maize. Some RFLPs were shown to map to genomic regions containing virus and fungus resistance genes. Perfect cosegregation was observed between RGA loci and the rust resistance loci $r p 1$ and $r p 3$. The RGA probe associated with $r p 1$ also detected deletion events in several $r p 1 \mathrm{mu}-$ tants. These data strongly suggest that some of the RGA clones may hybridize to resistance genes.
\end{abstract}

Genes conferring gene-for-gene disease resistance that have been isolated from plants can be categorized into four classes based on their predicted protein products. The majority of these genes belong either to a class encoding a stretch of leucine rich repeats (LRRs) and a putative nucleotide binding site (NBS) (Bent et al. 1994; Mindrinos et al. 1994; Whitham et al. 1994; Grant et al. 1995; Lawrence et al. 1995; Anderson et al. 1997; Ori et al. 1997; Parker et al. 1997; Yoshimura et al. 1998), or to a class that encodes an LRR domain but no NBS (Jones et al. 1994; Dixon et al. 1996). The third and fourth classes each have only one known representative and are characterized by proteins containing LRRs and a serinethreonine protein kinase domain but no NBS (Song et al. 1995), or by proteins that contain a protein kinase domain with no NBS or LRRs (Martin et al. 1993).

Resistance genes encoding a putative NBS and LRRs (NBS-LRR resistance genes) have been cloned from a number of dicot plant species and confer resistance to bacteria, fungi,

Corresponding author: A. Pryor; E-mail: poss@pi.csiro.au

Nucleotide and/or amino acid sequence data are to be found at GenBank as accession numbers AF052399 and AF056150 to AF056161. and a virus. In addition, an NBS-LRR gene has been identified at the $\mathrm{Cre} 3$ nematode resistance locus of wheat (Lagudah et al. 1997). Genes of the NBS-LRR class are therefore widely distributed among flowering plants and provide resistance to a variety of plant pathogens.

To date, the isolation of resistance genes has required the difficult and complex procedures of map-based cloning and transposon tagging. Polymerase chain reaction (PCR) is one method that may allow a more efficient means of isolating further resistance genes. In recent studies, PCR primers based on short stretches of amino acids conserved among NBS-LRR resistance proteins were used to amplify resistance gene-like sequences from potato, soybean, Arabidopsis thaliana, rice, and barley (Kanazin et al. 1996; Leister et al. 1996, 1998; Yu et al. 1996; Aarts et al. 1998). Amino acid motifs targeted in these studies included the kinase-1a (P-loop) and kinase-2 motifs, which are known features of NBSs (Saraste et al. 1990; Traut 1994), and other conserved motifs of unknown function. Restriction fragment length polymorphism (RFLP) loci identified by some of these resistance gene analog (RGA) clones were shown to be closely linked to known resistance loci, suggesting that the RGA clones may hybridize to resistance genes. In this study, we have applied the PCR approach to isolate resistance genes from maize.

\section{RESULTS}

The PCR isolation of 11 RGA sequences from maize.

Six amino acid motifs were used to design sets of oligonucleotide primers for the amplification of RGAs (Fig. 1 and Table 1). While four of the primers sets were based solely on amino acid motifs conserved among known resistance proteins (P-loop, kinase-2, GLPL, and MHD primer sets), the design of the remaining two primer sets was also influenced by similarities between resistance proteins and the products of RGAs isolated in this study (CFA and WMA primer sets). No introns are present between the primer sites in known resistance genes, so it was assumed that the size of PCR products arising from genomic RGA sequences could be predicted for any pair of primer sets (see Figure 1). Sequences containing a continuous open reading frame encoding internal amino acid motifs conserved in resistance proteins were defined as RGAs, and were investigated further. RGA sequences could be grouped into classes on the basis of nucleotide sequence identity, with sequences from within a class showing at least 
95\% nucleic acid identity (with the one exception described below), and sequences from different classes showing less than $70 \%$ identity.

PCRs from maize genomic DNA typically yielded a mixture of DNA fragments of a variety of sizes (not shown). A sample of 30 products of the expected size amplified with the P-loop and GLPL primer sets was sequenced and three classes of RGA sequences identified among them (PIC11, PIC12, and PIC21). In an attempt to increase the specificity of the PCR for RGAs, other experiments were carried out with a nested primer approach involving a second-round PCR with one or two internal primers. Products amplified from genomic DNA with the P-loop/MHD primer combination or the P-loop/ GLPL primer combination were used as template in a second round of amplifications with kinase-2/GLPL primer combinations. A number of these second-round reactions yielded prominent products of the expected size, and out of the 68 clones sequenced, 26 were RGAs. These included sequences from five new classes of RGAs (PIC13 to PIC17), and a sequence that showed $78 \%$ identity to the first PIC11 sequence, which was designated subclass PIC11-1. The PIC13 and PIC15 sequences of $300 \mathrm{bp}$, amplified in second-round PCRs with kinase-2/GLPL primers, were used as probes to screen libraries of cloned P-loop/MHD first-round products to obtain longer versions of these sequences.

In initial experiments, RGA sequences from the same class were often cloned and sequenced more than once. Clones obtained in further experiments were therefore screened by dot blot hybridization analysis with DNA probes made from previously characterized classes of maize RGAs in order to identify nonhybridizing clones representing potentially novel classes of RGAs suitable for sequencing. More than 700 clones were processed in this way. In these later experiments, PCRs were performed with the kinase-2/WMA primers followed by nested PCRs with the kinase-2/CFA primers. This yielded the RGAs PIC18 and PIC20. Amplification was also carried out with the kinase-2/WMA primers followed by kinase-2/GLPL primers, yielding PIC19.

Searches of the sequence data bases with the BLASTX computer program (Gish and States 1993) revealed significant levels of similarity between the predicted products of the maize RGA sequences and the products of known NBS-LRR resistance genes. In general, levels of similarity were greater with the $I 2 C-1$ vascular wilt disease resistance gene of tomato and the RPM1 and RPS2 Pseudomonas syringae resistance genes of $A$. thaliana than with other NBS-LRR resistance genes such as $L 6$ for flax rust resistance in flax and $N$ for tobacco mosaic virus resistance in tobacco. In addition, significant amino acid similarity was observed between the RGA clones and other clones described as RGAs on the data base, such as clones obtained by a PCR approach from potato and soybean (Leister et al. 1996; Kanazin et al. 1996; Yu et al. 1996). Regions of amino acid similarity between the predicted products of the maize RGA clones and known NBS-LRR resistance proteins are illustrated in Figure 1. As the primer sequences were always expected to be present in the clones, ad-
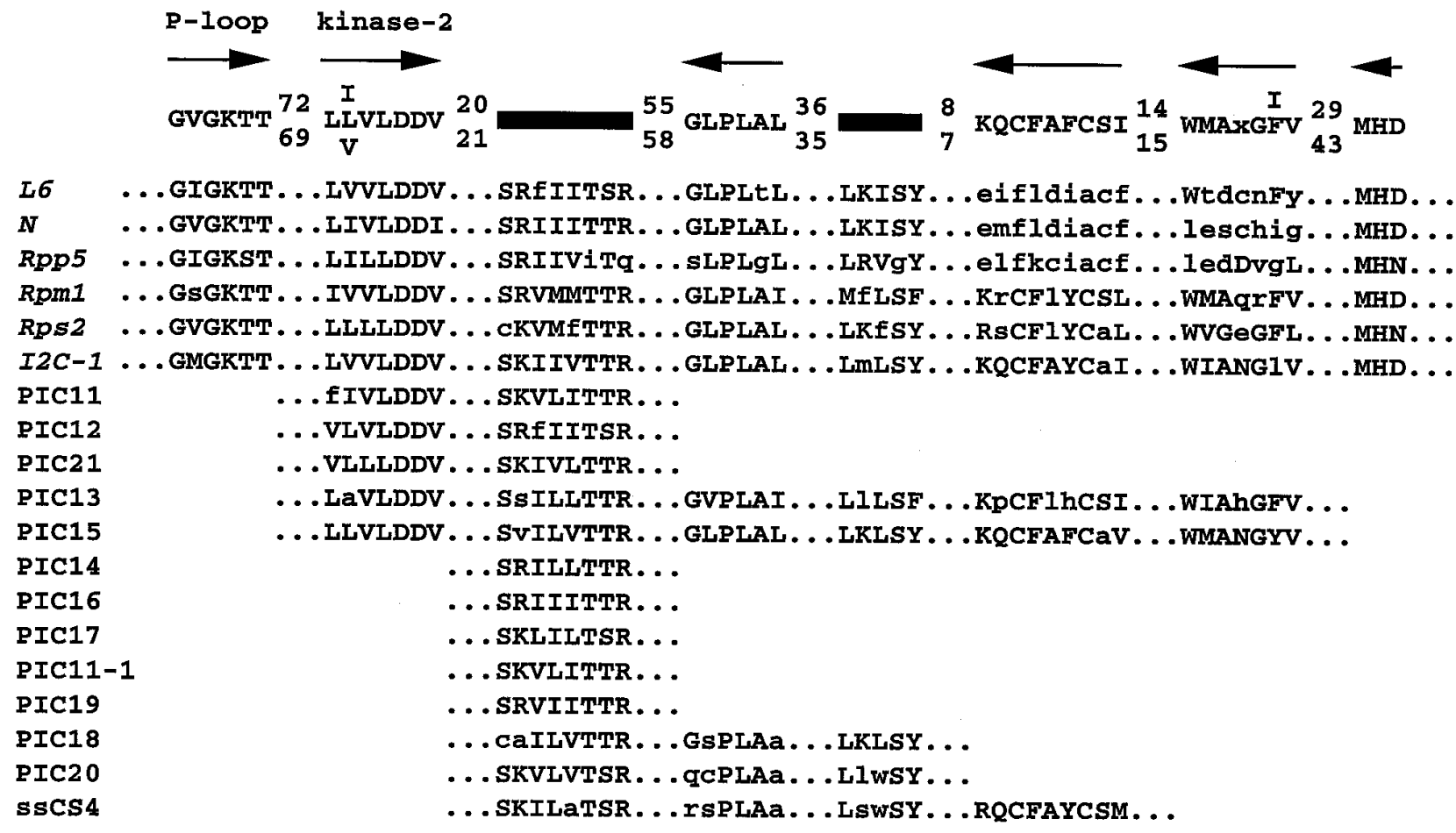

Fig. 1. Eight regions of amino acid similarity between products of dicot nucleotide binding site-leucine rich repeat (NBS-LRR) resistance genes $L 6, N$, Rpp5, Rpm1, Rps2, and $I 2 C-1$, and predicted products of the resistance gene analog (RGA) sequences isolated from maize (PIC11 to PIC21) and wheat (ssCS4). Similar residues are in uppercase; sequences between motifs are represented by dots. Average lengths of intervening sequences are shown for resistance genes and RGAs by upper and lower figures, respectively. Consensus sequences used to design oligonucleotide primer sets are shown; arrows indicate primer orientations. Sequences amplified with the same final primer sets are grouped together. Amino acids derived from final primers are not shown, as they may not reflect the true sequences of the RGA genes. Conserved internal motifs not used to design primers indicated by bars. GenBank accession numbers of RGAs are AF052399 and AF056150 to AF056161. 
ditional BLASTX searches were conducted with the primer sequences removed as a final check of similarity between the intervening sequences and known resistance genes. In this more stringent test, similarity with known resistance proteins was still observed for each clone, with a significance of 0.034 (PIC14) to $5.0 \mathrm{e}^{-39}$ (PIC13).

\section{Chromosomal locations of RGA loci in maize.}

To determine whether the maize RGA clones may hybridize to resistance genes, the RGA clones were used as probes to map RFLP loci in maize. In addition, the RGA clone ssCS4 previously isolated from wheat by Seah et al. (Seah et al., in press; see also Figure 1) was used to map RFLP loci in maize.

When used as a probe on the DNA of the parents of the maize mapping populations, PIC11-1, which showed 78\% nucleotide sequence identity to PIC11, gave the same complex hybridization pattern as PIC11, except that each of the two probes emphasized different restriction fragments (not shown). Subsequent mapping with the two probes verified that they hybridize to the same genetic locus. Unique hybridization patterns were shown by each of the other 10 classes of maize RGAs and the wheat RGA clone ssCS4.

The mapping of RFLPs with RGA probes was mainly performed with the 54 individuals from the Tx303 $\times$ CO159 University of Missouri-Columbia immortalized $\mathrm{F}_{2}$ family (Gardiner et al. 1993). Only the probes PIC12 and PIC21 failed to identify polymorphisms between the parents of this population and were instead used to map polymorphisms identified in an $\mathrm{H} 99 \times$ Mo17 recombinant inbred family de- veloped by Mike Lee (Iowa State University). For each probe except PIC13, a restriction enzyme could be found that enabled all visible hybridization bands to be mapped. PIC13 showed the most complex hybridization pattern (Fig. 2A) and identified at least one nonpolymorphic restriction fragment for each restriction enzyme tested. Mapping with PIC13 was therefore performed with a number of restriction enzymes in the immortalized $F_{2}$ population as well as in two recombinant inbred families from Brookhaven National Laboratory (Burr and Burr 1991) in an attempt to map all loci this probe hybridizes to in the maize genome. Loci detected by PIC18 and PIC19 were also mapped in the BNL recombinant inbred families to determine linkage between these loci and other relevant molecular markers not scored in the immortalized $F_{2}$ population (see below).

A summary of the genome-wide mapping is presented in Figure 3. While the clones PIC11, PIC12, PIC14, PIC15, PIC16, PIC17, PIC19, PIC20, and PIC21 each identified a single locus, clones PIC13, PIC18, and ssCS4 detected four, two, and five loci, respectively. Hence, a total of 20 RFLP loci were mapped. Three different types of RFLP loci were observed: "complex" loci that showed a small family of restriction fragments that co-segregated as an allele of a single locus (pic13b, pic19, and pic20); "dominant" loci for which hybridizing restriction fragments from only one of the parents could be seen (pic13a, pic13c, ssCS4a, ssCS4c, and ssCS4e); and "simple codominant" loci represented by a single pair of allelic restriction fragments (all other loci). Examples of the first two classes of loci are illustrated in Figure 2.

Table 1. Oligonucleotide primers used to amplify resistance gene analogs (RGAs)

\begin{tabular}{|c|c|c|}
\hline Conserved amino acid motif & Primer name & Primer sequence $\left(5^{\prime} \text { to } 3^{\prime}\right)^{a}$ \\
\hline GVGKTT (P-loop) & $\begin{array}{l}\text { P-loop1 } \\
\text { P-loop2 } \\
\text { P-loop3 } \\
\text { P-loop4 } \\
\text { P-loop5 } \\
\text { P-loop6 } \\
\text { P-loop7 } \\
\text { P-loop8 }\end{array}$ & $\begin{array}{l}\text { AAGAATTCGGNGTNGGNAAAACAAC } \\
\text { AAGAATTCGGNGTNGGNAAAACTAC } \\
\text { AAGAATTCGGNGTNGGNAAAACCAC } \\
\text { AAGAATTCGGNGTNGGNAAAACGAC } \\
\text { AAGAATTCGGNGTNGGNAAGACAAC } \\
\text { AAGAATTCGGNGTNGGNAAGACTAC } \\
\text { AAGAATTCGGNGTNGGNAAGACCAC } \\
\text { AAGAATTCGGNGTNGGNAAGACGAC }\end{array}$ \\
\hline L(I/V/L)VLDDV (kinase-2) & $\begin{array}{l}\text { Kinase-2D } \\
\text { Kinase-2E } \\
\text { Kinase-2F } \\
\text { Kinase-2G }\end{array}$ & $\begin{array}{l}\text { CTACTGNTNCTNGACGACGT } \\
\text { CTACTGNTNCTNGACGATGT } \\
\text { CTACTGNTNCTNGATGACGT } \\
\text { CTACTGNTNCTNGATGATGT }\end{array}$ \\
\hline GLPLAL & $\begin{array}{l}\text { GLPL1 } \\
\text { GLPL2 } \\
\text { GLPL3 } \\
\text { GLPL4 } \\
\text { GLPL5 } \\
\text { GLPL6 }\end{array}$ & $\begin{array}{l}\text { AACTCGAGAGNGCNAGNGGNAGGCC } \\
\text { AACTCGAGAGNGCNAGNGGNAGACC } \\
\text { AACTCGAGAGNGCNAGNGGNAGTCC } \\
\text { AACTCGAGAGNGCNAGNGGNAGCCC } \\
\text { AACTCGAGAANGCCAANGGCAATCC } \\
\text { AACTCGAGAANGCCAANGGCAAACC }\end{array}$ \\
\hline KQCFAFCSI & $\begin{array}{l}\text { CFA1 } \\
\text { CFA2 } \\
\text { CFA3 } \\
\text { CFA4 }\end{array}$ & $\begin{array}{l}\text { CAA/GT/AAIGCG/AAAG/ACAC/TTGTTT } \\
\text { CAA/GT/AAIGCG/AAAG/ACAC/TTGCTT } \\
\text { ATAGAA/GCAA/GT/AAIGCG/AAAACA } \\
\text { ATAGAA/GCAA/GT/AAIGCG/AAAGCA }\end{array}$ \\
\hline WMAxG(F/I)V & $\begin{array}{l}\text { WMA1 } \\
\text { WMA2 } \\
\text { WMA3 } \\
\text { WMA4 }\end{array}$ & $\begin{array}{l}\text { AT/CA/GAANCCNTNAGCCATCCA } \\
\text { AT/CA/GAANCCNTNTGCCATCCA } \\
\text { AT/CA/GAANCCNTNCGCCATCCA } \\
\text { AT/CA/GAANCCNTNGGCCATCCA }\end{array}$ \\
\hline MHD & $\begin{array}{l}\text { MHD1 } \\
\text { MHD2 } \\
\text { MHD3 } \\
\text { MHD4 }\end{array}$ & $\begin{array}{l}\text { CGACAGTCNATCATGCAT } \\
\text { CGACAGTCNATCGTGCAT } \\
\text { CGACAGTCNGTCATGCAT } \\
\text { CGACAGTCNGTCGTGCAT }\end{array}$ \\
\hline
\end{tabular}

${ }^{a}$ P-loop and GLPL primer sequences were based on primers used by Shen et al. (1998). 

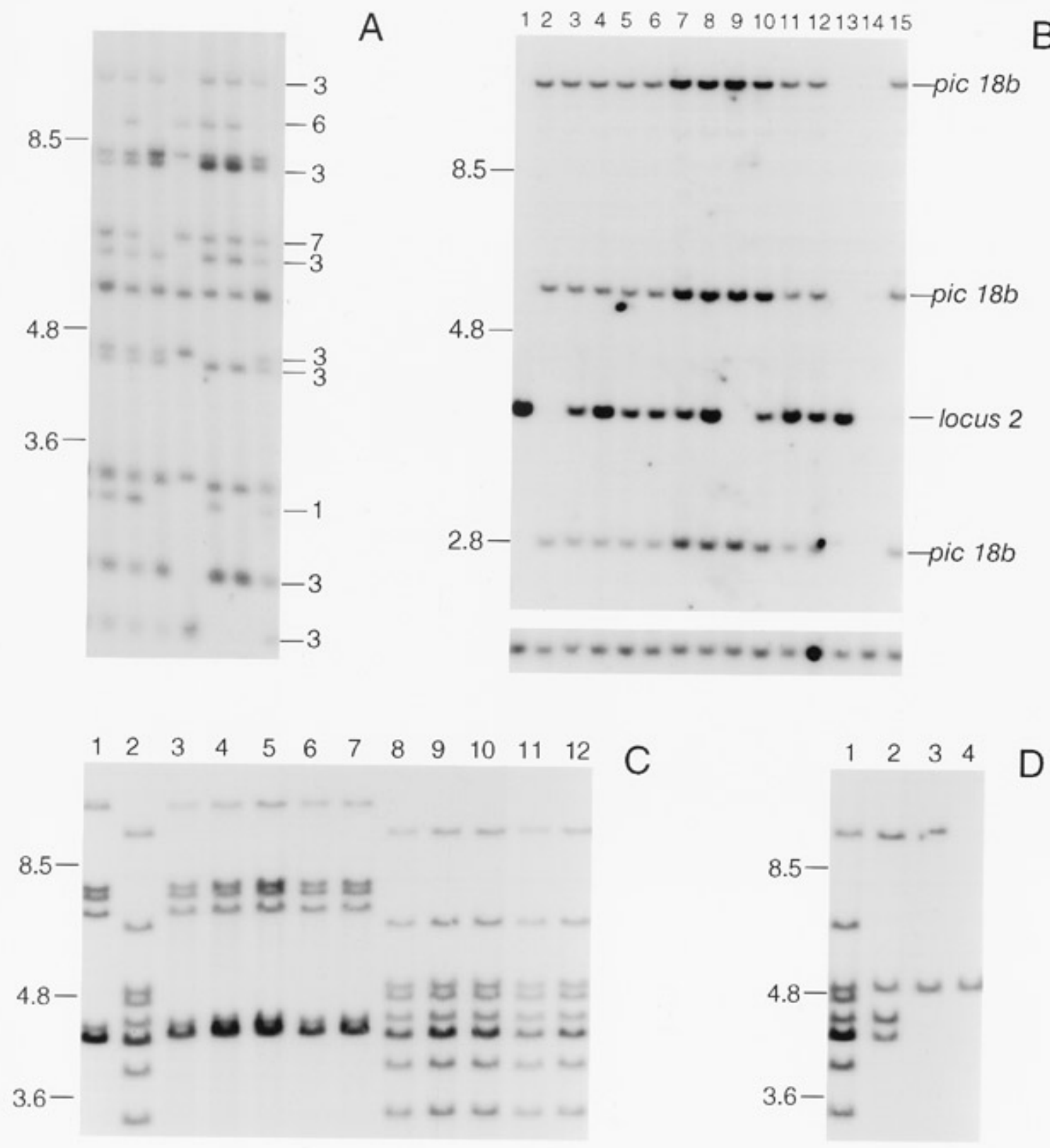

Fig. 2. Southern hybridization analysis of maize segregating families and mutants, with the resistance gene analog (RGA) probes PIC13, PIC18, and PIC20. Sizes of DNA size standards are shown (in kbp) to the left of each panel. A, DNA of individuals from maize Tx303 $\times \mathrm{CO} \mathrm{C}_{5}$ immortalized $\mathrm{F}_{2}$ family cut with NsiI and probed with PIC13. Restriction fragments mapping to loci on chromosomes 1, 3, 6, and 7 are indicated. B, DNA of individuals from $r p 4$ segregating family cut with AccI and probed with PIC18. Lane 1, resistant parent; lanes 2 to 10, homozygous susceptible segregants; lanes 11 to 15 , homozygous or heterozygous resistant segregants. Susceptible parent was heterozygous at the rp4 locus and is not shown. Three restriction fragments derived from susceptible parent were at a locus linked to $r p 4$ (picl $18 b$ ), while another fragment derived from resistant parent segregated independently of rp4 (locus 2). Segregation of the two dominant loci resulted in complete absence of restriction fragments hybridizing to PIC18 in one resistant segregant (lane 14). Five homozygous susceptible individuals resulting from recombination distal to $r p 4$ (between $r p 4$ and the restriction fragment length polymorphism (RFLP) marker agrr115), and the four homozygous susceptible individuals resulting from proximal recombination (between $r p 4$ and the $s s C S 4 b$ locus) are shown in lanes $2-6$ and 7-10, respectively. Hybridization to the pic $18 b$ fragments was approximately half as intense in the distal recombinants as in the proximal recombinants, indicating that pic $18 \mathrm{~b}$ is distal to $r p 4$. Hybridization of the same filter to the PIC15 probe was used to demonstrate even loading of DNA (inset). C, DNA of individuals homozygous for Rp1-M (lanes 3-7) or homozygous for Rp1-D (lanes 8-11) selected from a single $\mathrm{F}_{2}$ mapping population, cut with $N \mathrm{coI}$, and probed with PIC20. Hybridizing restriction fragments from the Rpl-M parent (lane 1) or the Rp1-D parent (lane 2) co-segregated with one another and with the respective $r p 1$ allele. D, DNA of susceptible mutants of $R p 1-D$ cut with $N c o$ I and probed with PIC20. Probe detected eight bands in the Rp1-D parent (lane 1), but only four, two, and one bands in the susceptible mutants $R p 1-D^{*}-1$, $R p 1-D^{*}-4$, and $R p 1-D^{*}-24$, respectively (lanes $2-4$ ). 
RGA loci were mapped to genomic regions known to contain resistance loci.

Six regions of the maize genome were found to contain RGA loci in close proximity to known disease resistance loci (Fig. 3).

The RGA probe PIC15 detected an RFLP locus on the long arm of maize chromosome 1, 6.5 centimorgans (cM) distal to the RFLP marker php20644. The $h m l$ gene for resistance to carbonum leaf spot (causal agent: Cochliobolus carbonum R. R. Nelson) has previously been mapped $5.0 \mathrm{cM}$ distal to php20644 (Johal and Briggs 1990), indicating that the pic15 locus is closely linked to $h m 1$. However, PIC15 was not derived from $h m l$, as the $h m l$ gene has been isolated and encodes a reductase enzyme that does not contain a putative NBS (Johal and Briggs 1992).

The RGA probe PIC18 detected the locus pic18a on the long arm of maize chromosome 2, close to the htl locus for resistance to northern corn leaf blight (causal agent: Helminthosporium turcicum Pass.) (Fig. 3). htl had previously been mapped $5.4 \mathrm{cM}$ from the RFLP marker bnl6.20 (Bentolila et al. 1991). The bnl6.20 marker had been scored in the CO159 × Tx303 recombinant inbred family, and in the 41 lines, pic18a showed no recombination with bnl6.20.

The RGA probe PIC13 detected a complex locus in the middle of chromosome 3 near a cluster of resistance loci that includes $r p 3$, wsml, and $m v 1$, for resistance to maize common rust (causal agent: Puccinia sorghi (Schwein.)), wheat streak mosaic virus, and maize mosaic virus, respectively. The rp3 locus had previously been mapped to the $5.0 \mathrm{cM}$ interval between the two RFLP markers umc102 and umc10a (SanzAlferez et al. 1995), while wsml and $m v 1$ had both been mapped outside this interval, below umc102 (McMullen et al. 1994; Ming et al. 1997). In this exercise, the pic13b locus detected by PIC13 was located between umc102 and umc10a $(\mathrm{LOD}=3.8)$. Hence, the pic13b locus was identified as a candidate for $r p 3$ but was shown to be an unlikely candidate for wsml or $m v 1$.

Two loci were detected by the RGA probes PIC18 and ssCS4 on the short arm of chromosome 4 that contains the rp4 locus for resistance to maize common rust. The $r p 4$ locus had previously been mapped only with respect to morphological markers (Coe and Neuffer 1977) so its precise location relative to RFLP markers was unknown. Therefore, prior to the further mapping information obtained in this study (next section), it was not possible to rule out either of these RGA loci as candidates for $r p 4$.

The RGA probes PIC19 and ssCS4 both detected loci on chromosome 6 near the loci $r h m l$, wsml, and $m d m l$ for resistance to northern corn leaf blight (causal agent: Helminthosporium turcicum), wheat streak mosaic virus, and maize

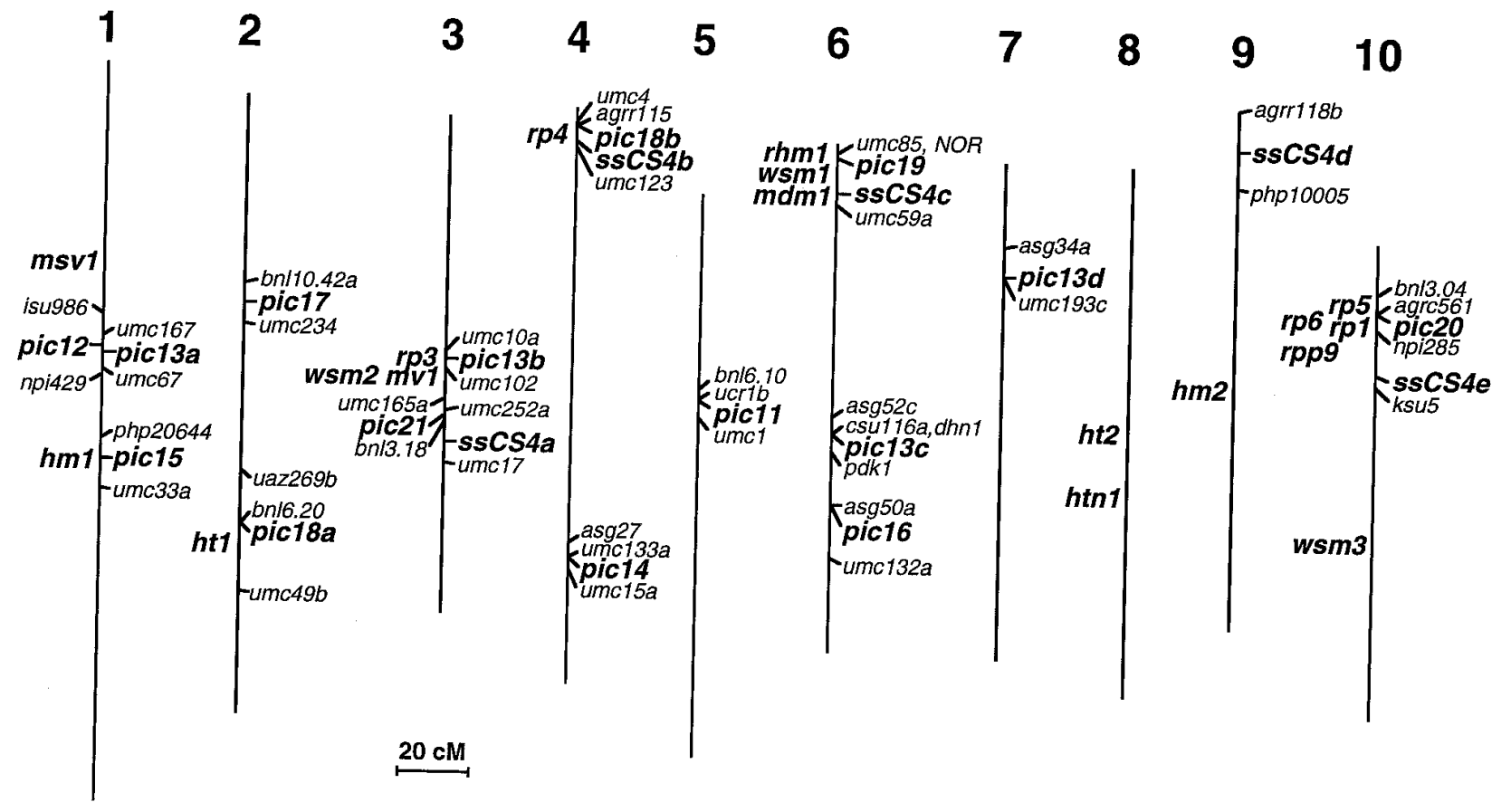

Fig. 3. Summary of genome-wide restriction fragment length polymorphism (RFLP) mapping data obtained in maize with maize resistance gene analog (RGA) probes PIC11 to PIC21 and the wheat RGA probe ssCS4, with one immortalized $F_{2}$ population and three recombinant inbred populations. Independently segregating loci detected by single probes are distinguished by letters (e.g., pic13a, pic13b, pic13c). Selected RFLP markers previously scored in the mapping populations, including any co-segregating RFLP markers, have been included to define RGA loci positions. Orders of RGA loci pic12 and pic 21 relative to other loci are uncertain as these loci were mapped with different mapping populations (see text). Approximate locations of known disease resistance are shown. $m s v l=$ resistance to maize streak virus (Kyetere et al. 1995); $h m$ loci = resistance to carbonum leaf spot (causal agent: Cochliobolus carbonum H. R. Nelson) (Nelson and Ullstrup 1964; Johal and Briggs 1990); rp loci = resistance to maize common rust (causal agent: Puccinia sorghi Schwein.) (Coe and Neuffer 1977; Wilkinson and Hooker 1968; Hulbert and Bennetzen 1991); rpp9= resistance to maize southern rust (causal agent: Puccinia polysora Underw.) (Ullstrup 1965), wsm loci = resistance to wheat streak mosaic virus (McMullen et al., 1994; Simcox et al., 1995), $m v 1$ = resistance to maize mosaic virus (Ming et al. 1997); rhm1 = resistance to southern corn leaf blight (causal agent: Cochliobolus heterostrophus Dresch.) (Zaitlin et al. 1993); $m d m 1$ = resistance to maize dwarf mosaic virus (Simcox et al. 1995). ht 1 , ht2, and $h t n 1=$ resistance to northern corn leaf blight (causal agent: Helminthosporium turcicum Pass.) (Bentolila et al. 1991; Zaitlin et al. 1992; Simcox and Bennetzen 1993). 
dwarf mosaic virus, respectively. The $m d m l$ locus has been shown by Simcox et al. (1995) to be very tightly linked to the nucleolus organizer $(N O R)$. However, with the two BNL recombinant inbred populations that had been characterized for the NOR locus, the RGA locus pic19 was shown to map 4.8 $\mathrm{cM}$ below the NOR. The RGA locus $s s C S 4 c$ was mapped below pic19. Hence, pic19 and $s s C S 4 c$ are both unlikely candidates for $m d m l$. The wsml locus had been mapped to the interval of approximately $14 \mathrm{cM}$ delineated by the RFLP markers umc59a and umc85 (McMullen et al. 1994). Zaitlin et al. (1993) showed that rhml was also located close to umc85, but could not resolve whether rhml was located between $u m c 59 a$ and $u m c 85$, or above $u m c 85$. This study located the pic19 and $s s C S 4 c$ loci to the umc59a-umc85 interval (LODs = 1.29 and 1.0, respectively), identifying both of these RGA loci as candidates for wsml or rhml.

The RGA probes PIC20 and ssCS4 detected loci on the short arm of chromosome 10, which carries the $r p 1, r p 5$, and rp6 loci for maize common rust (Hooker 1985) and the rpp9 locus for maize southern rust (causal agent: P. polysora Underw.) (Ullstrup 1965). The rpl and rp5 loci have been located in the interval of 4.0 to $12 \mathrm{cM}$ delimited by the RFLP markers npi285 and bnl3.04 (Hulbert and Bennetzen 1991). The pic20 locus was mapped to this same interval (LOD = 3.6) that made it a candidate for $r p 1$ and $r p 5$, while the ssCS4e locus was mapped outside of this interval, below npi285. It is unclear how close the pic20 and ssCS4e loci are to rp6 and rpp9, as these resistance loci have not been mapped relative to RFLP markers.

Table 2. Analysis of recombinants between $r p 3$ and $y s 3$

\begin{tabular}{|c|c|c|c|c|}
\hline \multirow[b]{2}{*}{ Parents and progeny } & \multicolumn{4}{|c|}{ Genotypes at marker loci } \\
\hline & $r p 3$ & pic13b & umc10 & $y s 3$ \\
\hline \multicolumn{5}{|l|}{ Parents } \\
\hline Parent 1 (P1) & Rp3/Rp3 & $+/+$ & $+/+$ & $Y s 3 / Y s 3$ \\
\hline Parent 2 (P2) & rp3/rp3 & $-1-$ & $-1-$ & $y s 3 / y s 3$ \\
\hline \multicolumn{5}{|l|}{$(\mathrm{P} 1 \times \mathrm{P} 2) \times \mathrm{P} 2$ progeny } \\
\hline Recombinant 1 & $r p 3 / r p 3$ & $-1-$ & $+/-$ & Ys3/ys3 \\
\hline Recombinant 2 & $r p 3 / r p 3$ & $-1-$ & $-1-$ & Ys3/ys3 \\
\hline Recombinant 3 & $r p 3 / r p 3$ & $-1-$ & $+/-$ & Ys3/ys3 \\
\hline Recombinant 4 & Rp3/rp3 & $+/-$ & $+/-$ & $y s 3 / y s 3$ \\
\hline Recombinant 5 & Rp3/rp3 & $+/-$ & $-1-$ & ys $3 / y s 3$ \\
\hline Recombinant 6 & Rp3/rp3 & $+/-$ & $-1-$ & ys $3 / y s 3$ \\
\hline
\end{tabular}

Table 3. Analysis of recombinants between $r p 3$ and $g l 6$

\begin{tabular}{|c|c|c|c|c|c|}
\hline \multirow[b]{2}{*}{ Parents and progeny } & \multicolumn{5}{|c|}{ Genotypes at marker loci } \\
\hline & umc10 & $r p 3$ & pic13b & umc102 & gl6 \\
\hline \multicolumn{6}{|l|}{ Parents } \\
\hline Parent 1 (P1) & $+/+$ & $R p 3 / R p 3$ & $+/+$ & $+/+$ & Gl6/Gl6 \\
\hline Parent 2 (P2) & $-1-$ & $r p 3 / r p 3$ & $-1-$ & $-1-$ & $\mathrm{gl} / \mathrm{gl} 6$ \\
\hline \multicolumn{6}{|l|}{$(\mathrm{P} 1 \times \mathrm{P} 2) \times \mathrm{P} 2$ progeny } \\
\hline Recombinant 1 & $-1-$ & $r p 3 / r p 3$ & $-1-$ & $+/-$ & Gl6/gl6 \\
\hline Recombinant 2 & $-1-$ & rp3/rp3 & $-1-$ & $+/-$ & Gl6/gl6 \\
\hline Recombinant 3 & $-1-$ & rp3/rp3 & $-1-$ & $+/-$ & Gl6/gl6 \\
\hline Recombinant 4 & $-1-$ & rp3/rp3 & $-1-$ & $+/-$ & Gl6/gl6 \\
\hline Reco & $-1-$ & rp3/rp3 & $-1-$ & $+/-$ & Gl6/gl6 \\
\hline Reco & $-1-$ & rp3/rp3 & $-1-$ & $+/-$ & Gl6/gl6 \\
\hline Recombinant 7 & $-1-$ & rp3/rp3 & $-1-$ & $+/-$ & Gl6/gl6 \\
\hline Recombinant 8 & $-1-$ & rp3/rp3 & $-1-$ & $+/-$ & Gl6/gl6 \\
\hline Recombinant 9 & $+/-$ & $R p 3 / r p 3$ & $+/-$ & $-1-$ & gl6/gl6 \\
\hline Recombinant 10 & $+/-$ & $R p 3 / r p 3$ & $+/-$ & $-1-$ & gl6/gl6 \\
\hline
\end{tabular}

Examination of populations segregating for rust resistance at the rp1, rp3, and rp4 loci.

In the first stage of this study, a number of RGA loci were found to map to genomic regions of maize that were known to contain resistance loci. In the second stage, families segregating for the $r p 1, r p 3$, and $r p 4$ rust resistance loci were examined to test the linkage between these three resistance loci and closely linked RGA loci more rigorously.

A small backcross family of 50 individuals segregating for the $R p 3-D$ allele of $r p 3$ was used to obtain a first indication of linkage between the rp3 locus and the locus detected by the RGA clone PIC13 on chromosome 3. In this family, PIC13 identified an HpaII restriction fragment of approximately 2.0 kbp from the Rp3-D parent (not shown) that co-segregated with resistance. Further analysis was carried out with two larger families segregating for $R p 3-A$ and either of the two closely linked morphological marker loci ys 3 or gl6. The results are summarized in Tables 2 and 3. In these families, PIC13 identified polymorphic HpaII restriction fragments from the Rp3-A parents that were similar in size to the HpaII fragment observed in the $R p 3-D$ parent of the first family. Out of 800 individuals, six individuals resulting from recombination between rp3 and ys 3 were identified, and in these recombinants the HpaII restriction fragment showed perfect association with rp3. Similarly, from a population of 1,823, 10 individuals resulting from recombination between $r p 3$ and $g l 6$ were identified, and in these recombinants the HpaII fragment also showed perfect association with $r p 3$. Analysis of the ys3$r p 3$ recombinants with the RFLP marker umc10 placed umc10

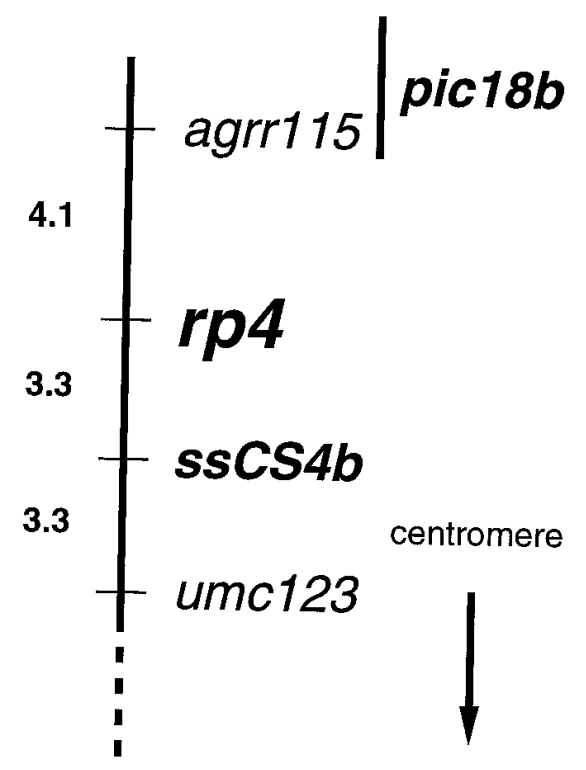

Fig. 4. Genetic map of the rp4 region of maize chromosome 4. Restriction fragment length polymorphism (RFLP) loci agrr115 and umc123 were detected with probes made from cDNA and genomic DNA sequences of unknown function, respectively, while pic $18 b$ and $s s C S 4 b$ loci were detected with resistance gene analog (RGA) probes isolated from maize and wheat, respectively. Previously determined locations of agrr115 and umc123 (Coe et al. 1995) enabled map to be oriented with respect to the centromere. Location of pic $18 \mathrm{~b}$ locus alongside or distal to agrr115 was determined by analyzing recombinants observed for the ssCS4b-agrr115 interval only (see Figure 2B). Genetic distances are in centimorgans. 
between ys3 and $r p 3$, while in the recombinants for the gl6rp3 interval the RFLP marker umc102 co-segregated with gl6. As $u m c 10$ and $u m c 102$ had been previously mapped to opposite sides of rp3 (Sanz-Alferez et al. 1995), this result indicated that the two morphological markers also flank rp3. Failure to detect recombination between $r p 3$ and the pic13b RFLP in recombinants for $r p 3$ and these closely flanking morphological markers indicated that the pic $13 b$ locus is very tightly linked to or coincident with $r p 3$.

Linkage to $r p 4$ was tested with 60 homozygous susceptible individuals derived from an $\mathrm{F}_{2}$ family segregating for $R p 4-A$. This analysis resulted in the construction of a genetic map of the rp4 region of maize chromosome 4 (Fig. 4). Individuals from this population were analyzed with the RGA clones ssCS4 and PIC18, in addition to the RFLP markers agrr 115 and $u m c 123$, which had previously been located to the $r p 4$ region (Coe et al. 1995). The markers agrr115 and umc123 were mapped to either side of $r p 4$ at distances of 4.1 and 6.6 $\mathrm{cM}$, respectively. The ssCS4 probe detected a pair of allelic $A c c 1$ restriction fragments that segregated in the mapping population and that were linked to rp4 (not shown). Four recombinants were observed between this RFLP and $r p 4$, placing it proximal to $r p 4$. All of the $A c c 1$ restriction fragments identified by PIC18 were polymorphic between the two parents, allowing the detection of two independently segregating loci (Fig. 2B). The first of these consisted of a single hybridizing restriction fragment from the resistant parent that was unlinked to $r p 4$ and therefore likely to represent the chromosome 2 locus pic18a identified in the previous section. The second locus consisted of three co-segregating restriction fragments from the susceptible parent that were linked to $r p 4$. The absence of hybridizing $r p 4$-linked restriction fragments from the resistant parent demonstrated that PIC18 hybridizing sequences were not essential for $r p 4$-mediated resistance. In addition, recombinants were identified between $r p 4$ and the linked picl $8 b$ locus, indicating that this locus was distal to $r p 4$ (Figs. 2B and 4). Thus, the picl8b and $s s C S 4 b$ loci closely flanked the $r p 4$ locus and both were eliminated as candidates for $r p 4$.

Linkage to $r p l$ was tested with 18 homozygous $R p l-M$ individuals and 20 homozygous $R p l-D$ individuals that had been selected from a single $\mathrm{F}_{2}$ population segregating for $R p l$ $M$ and $R p 1-D$ in repulsion. With the restriction enzyme $N c o$ I, the PIC20 RGA probe detected four polymorphic restriction fragments from the $R p 1-M$ parent, six polymorphic restriction fragments from the $R p 1-D$ parent, and two restriction fragments that were monomorphic (Fig. 2C). The polymorphic restriction fragments from each parent segregated together and showed perfect linkage to the respective resistance allele at $r p 1$, indicating that the pic20 locus is closely linked or coincident with rpl.

\section{Analysis of Rp1-D mutants with PIC20.}

To further test the hypothesis that PIC20 hybridizes to resistance genes at the $r p l$ locus, the probe was used in the Southern analysis of susceptible mutants of $R p 1-D$ thought to have arisen by unequal crossing over (Pryor 1993). In NcoIrestricted DNA of the resistant $R p 1-D$ parent, PIC20 gave eight hybridization bands (Fig. 2D). However, in the homozygous, susceptible mutants $R p 1-D^{*}-1, R p 1-D^{*-4}$, and Rpl-D*24 , only four, two, and one bands were detected, respectively (Fig. 2D). The absence of some hybridizing restriction frag- ments in these $R p 1-D$ mutants demonstrated that deletion events at or close to $r p l$ were concomitant with loss of resistance, and strongly supports the hypothesis that PIC20 hybridizes to a resistance gene family present at $r p 1$.

\section{DISCUSSION}

\section{How effective is the PCR approach in isolating disease resistance genes?}

In this exercise, 11 classes of RGAs were PCR amplified from maize genomic DNA with primers based on amino acid motifs conserved among known disease resistance proteins. These maize RGA clones and one wheat RGA clone were used to map 20 RFLP loci in the maize genome. Many of the RFLP loci were mapped to chromosomal regions known to contain resistance genes. Notable examples were the loci identified by the RGA clones PIC13 and PIC20 on chromosomes 3 and 10, respectively, which were mapped to the same $<5$ cM RFLP marker intervals to which rust resistance genes had previously been mapped. Furthermore, in populations segregating for either the $r p 1$ or $r p 3$ rust resistance genes no recombination was observed between the resistance genes and closely linked RGA loci. Overall, the PCR approach resulted in the generation of a number of RGA sequences, some of which detected loci that are now good candidates for known disease resistance loci.

This study failed to identify candidate RGA loci for many of the known disease resistance loci in maize. For example, no RGA loci were mapped in the vicinity of the $h t 2$ or $h t n 1$ genes for resistance to the northern corn leaf blight fungus, the $h \mathrm{~m} 2$ gene for resistance to the carbonum leaf spot fungus, or the $m s v l$ gene for maize streak virus resistance. Loci identified by the RGA probes PIC18 and ssCS4 close to the rust resistance locus $r p 4$ were shown to be distinct from $r p 4$, as recombination events were observed between these RGA loci and the rust resistance loci in a segregating population. In addition, the pic13b RGA locus was likely to be distinct from the closely linked viral resistance genes $w s m 2$ and $m v 1$ on the basis of the placement of the RFLP marker umc102 between pic $13 b$ and these virus resistance genes.

The inability to identify RGA loci coincident with certain disease resistance loci may reflect the fact that not all resistance genes in maize belong to the NBS-LRR class (e.g., $h m l)$. In addition, the search for maize RGAs was not exhaustive. This can be illustrated by the fact that homologs of the wheat RGA ssCS4 were not isolated from maize, even though hybridization of this clone to maize DNA indicated that homologs of ssCS4 were present in the maize genome. In A. thaliana, sequences hybridizing to the NBS-LRR resistance gene RPMI were totally absent from some lines (Grant et al. 1995), suggesting that different lines of a plant species contain different sets of NBS-LRR gene classes. This is similar to the situation for the maize RGA probe PIC18, in which two dominant segregating loci were detected in an $\mathrm{F}_{2}$ population, so that in some segregants sequences hybridizing to this probe were completely absent. The possibility that some RGA sequences may be absent in some maize lines should be considered when cloning and mapping RGAs. For example, the use of a number of different populations for mapping RGAs may lead to the detection of a greater number of loci.

Over 20 quantitative trait loci (QTL) influencing resistance to a range of pests and pathogens have been mapped in maize 
(reviewed by McMullen and Simcox 1995). Although it is possible that genes controlling resistance at some of these QTL may belong to the NBS-LRR class, an attempt was not made in this study to infer linkage between QTL and RGA loci, as the locations of most QTLs are poorly defined. However, one example of linkage can be seen between the RGA locus pic14 and a QTL controlling resistance to anthracnose stalk rot fungus (causal agent: Colletotrichum graminicola (Ces.) G. W. Wils.) on chromosome 4. The pic14 locus was mapped only $3.0 \mathrm{cM}$ from the RFLP locus umc15, and the QTL, controlling 70 to $85 \%$ of phenotypic variation in segregating populations, was also placed a few centimorgans from umc15 (Jung et al. 1994).

\section{Do RGA probes hybridize to resistance genes?}

Associations between RGA loci and known resistance loci were initially made by inference on the basis of similar chromosomal location, and a more rigorous test of linkage between these RGA loci and resistance genes required the analysis of populations segregating for the resistance genes themselves. The value of this test can be illustrated by the analysis of the $r p 4$ segregating population that resulted in the identification of recombination events between $r p 4$ and two closely linked RGA loci, allowing the elimination of these RGA loci as candidates for $r p 4$.

The rpl locus has 14 recognized "alleles" (Rpl-A to Rpl$N$ ), each of which confers resistance to a different biotype of maize common rust. Some of these alleles have been genetically recombined, suggesting that these represent closely linked members of a gene family (Saxena and Hooker 1968; Hooker and Saxena 1971; Hulbert and Bennetzen 1991). Studies with RFLP markers closely flanking $r p 1$ suggest that most spontaneous mutations of rpl alleles occur by unequal crossing-over events at the rpl locus (Hulbert and Bennetzen 1991; Sudupak et al. 1993). Alleles of $r p 1$ are therefore likely to reside on tandemly duplicated sequences that can mispair, resulting in the deletion of active members of the resistance gene family. In this study, members of a gene family perfectly linked to the $r p l$ locus were detected by the RGA probe PIC20, and some were deleted in spontaneous mutants of $R p 1$ $D$. These deletions are consistent with the model for instability at the rpl locus, although in this case flanking RFLP markers could not be used to verify whether the mutations were the result of recombination because the mutants were derived from a line homozygous for the flanking regions. More importantly, the observation strongly suggests that PIC20 hybridizes to a resistance gene family at the rpl locus, or at least to sequences present on repeats carrying members of such a resistance gene family.

Currently we are using further mutants of the $r p 1$ and $r p 3$ rust resistance loci to further test whether the PIC20 and PIC13 probes hybridize to resistance genes at these loci. Genes hybridizing to both of these probes have been isolated from maize and found to encode an LRR domain as well as an NBS, which is consistent with these genes belonging to the NBS-LRR class of resistance gene (A. Pryor and S. Hulbert, unpublished).

\section{Prospects.}

The wheat RGA probe ssCS4 hybridized to maize DNA and was used to map five loci in the maize genome. RGA clones isolated from rice and barley have also been found to hybridize to the DNA of a number of grass species (Leister et al. 1998). RGA clones isolated from cereals therefore represent a pool of clones that can be used to identify RGA loci in any one cereal species. Most of the RGA loci mapped in maize did not correspond to any known disease resistance gene. This may have been because these sequences provide resistance to pathogens that are unidentified or extinct, or because they have functions other than in providing disease resistance. While the results of this study suggest that RGA loci closely linked to resistance genes may be relatively easy to find, the task of proving whether these RGA clones are derived from the resistance genes themselves will be comparatively difficult unless the appropriate mutants are readily available. Many such sequences may in the first instance find a practical use as genetic markers that can be used to assist in the selection of disease resistance genes during breeding programs.

\section{MATERIALS AND METHODS}

\section{Oligonucleotide primers and PCR strategy.}

Six amino acid motifs conserved among known resistance proteins were used to design oligonucleotide primers for the PCR amplification of RGAs from maize (Table 1; Fig. 1). For each amino acid motif, a number of primers were made that varied at their $3^{\prime}$ ends to cover a range of possible sequences encoding the motif. The sequence at the $5^{\prime}$ end of the primers was constant for each set and was based on conserved amino acids, or was chosen at random. Figure 1 illustrates the regions of amino acid conservation upon which the primers were based and shows the orientation of the primers. PCR amplification from wheat DNA to give the RGA clone ssCS4 used a different set of primers and PCR strategy described by Seah et al. (in press).

Most of the PCR experiments involved a nested primer approach employing primers for three or four motifs. In the nested primer approach, PCR reactions were performed with all possible pairwise combinations of primers based on two amino acid motifs. The reactions were then combined into one or more pools, diluted, and used as template in second-round PCRs with either (i) all possible pairwise combinations of primers for two internal motifs or (ii) all possible pairwise combinations of primers for one internal motif and for one of the two motifs targeted in the first-round amplifications.

\section{PCR template and amplification conditions.}

Two preparations of maize genomic DNA were used as PCR template. The first was made with a $\mathrm{CsCl}$ gradient (Sambrook et al. 1989) from seedling leaf tissue of $F_{1}$ maize plants generated by crossing individuals homozygous for the Rp1-D and Rp1-M alleles of the rpl rust resistance locus. The second was prepared from the Black Mexican Sweet cell suspension culture developed by Chourey and Zurawski (1981), using a modified CTAB method (Saghai-Maroof et al. 1984).

First-round PCR reactions of $20 \mu \mathrm{l}$ volume contained 500 ng of genomic DNA, $0.2 \mathrm{mM}$ dATP, $0.2 \mathrm{mM}$ dTTP, $0.2 \mathrm{mM}$ $\mathrm{dCTP}$, and $0.2 \mathrm{mM} \mathrm{dGTP}, 0.25 \mu \mathrm{M}$ of each primer, $2.0 \mathrm{mM}$ $\mathrm{MgCl}_{2}, 50 \mathrm{mM} \mathrm{KCl}, 10 \mathrm{mM}$ Tris- $\mathrm{HCl}$ ( $\mathrm{pH} 9.0$ at $25^{\circ} \mathrm{C}$ ), and $0.1 \%$ Triton $\mathrm{X}-100$, and were subjected to thermal cycling in an FTS-1 Thermal Sequencer (Corbett Research, Sydney, Australia), with the following program: $95^{\circ} \mathrm{C}$ for $2 \mathrm{~min} ; 40$ 
cycles of $95^{\circ} \mathrm{C}$ for $30 \mathrm{~s}, 40^{\circ} \mathrm{C}$ for $30 \mathrm{~s}$ and $72^{\circ} \mathrm{C}$ for $2 \mathrm{~min} ; 10$ min at $72^{\circ} \mathrm{C}$ (except for first-round PCRs with the CFA primers for which an annealing temperature of $30^{\circ} \mathrm{C}$ was used).

Second-round amplifications were the same as above, except these were carried out in $10-\mu \mathrm{l}$ reactions containing $0.5 \mu \mathrm{l}$ of a $20 \times$ dilution of bulked, first-round PCR mix as template, and were subject to the following thermal cycling program: $95^{\circ} \mathrm{C}$ for $2 \mathrm{~min} ; 10$ cycles of $95^{\circ} \mathrm{C}$ for $30 \mathrm{~s}, 55^{\circ} \mathrm{C}$ for $30 \mathrm{~s}$ and $72^{\circ} \mathrm{C}$ for $50 \mathrm{~s} ; 25$ cycles of $95^{\circ} \mathrm{C}$ for $30 \mathrm{~s}, 50^{\circ} \mathrm{C}$ for $30 \mathrm{~s}$ and $72^{\circ} \mathrm{C}$ for $50 \mathrm{~s} ; 10 \mathrm{~min}$ at $72^{\circ} \mathrm{C}$.

\section{Cloning and sequence analysis of PCR products.}

PCR products were purified with Wizard PCR Preps columns (Promega, Madison, WI), or DNA fragments of the appropriate size were excised from agarose gels and purified with the Bresa-Clean II kit (Bresatec, Adelaide, Australia). Cloning was performed with the pGEM-T or pGEM-T Easy cloning kits (Promega). Plasmid DNA was purified by the boiling method (Sambrook et al. 1989) and used as template in sequencing reactions with the ABI Prism (Applied Biosystems, Foster City, CA) dye primer or dye terminator sequencing systems. Searches for similarity between the predicted protein products of clones and proteins on the data base were carried out with the BLASTX computer program (Gish and States 1993). Clones showing significant identity to known resistance proteins were analyzed further with programs from the University of Wisconsin Genetics Computer Group (GCG) package (Devereux et al. 1984) and GeneDoc (available online from the European Bioinformatics Institute).

\section{Probes, genetic stocks, and RFLP analysis.}

RGA clones used in RFLP analysis were the 11 maize sequences isolated by PCR in this study and the wheat RGA clone ssCS4. The ssCS4 sequence was amplified from genomic DNA of the wheat cultivar Chinese Spring by PCR and shows $74 \%$ nucleotide identity to the wheat NBS-LRR gene described by Lagudah et al. (1997) at the Cre3 nematode resistance locus. The RFLP clones agrr115 and umc123 detect loci in the rp4 region of maize chromosome 4 (Coe et al. 1995) and were obtained from the University of MissouriColumbia Maize RFLP Laboratory for the analysis of the $r p 4$ mapping family.

Genomic DNA for Southern analysis was cut with restriction enzymes according to the manufacturer's instructions (Promega), subjected to electrophoresis in 0.9 to $1.0 \%$ agarose gels (with approximately $3.0 \mu \mathrm{g}$ of DNA per lane), blotted to Hybond $\mathrm{N}^{+}$membrane (Amersham, Buckinghamshire, UK), and hybridized to $\alpha-{ }^{32} \mathrm{P}$-dCTP-labeled DNA probes made by random priming (Feinberg and Vogelstein 1983). Following hybridization at $65^{\circ} \mathrm{C}$, membranes were given three washes of $5 \mathrm{~min}$ at $55^{\circ} \mathrm{C}$ in $2.0 \times \mathrm{SSC}(1 \times \mathrm{SSC}$ is $0.15 \mathrm{M} \mathrm{NaCl}$ plus $0.015 \mathrm{M}$ sodium citrate), followed by two washes of $5 \mathrm{~min}$ at $55^{\circ} \mathrm{C}$ in $0.5 \times \mathrm{SSC}$. Autoradiography was carried out for 1 to 5 days at $-80^{\circ} \mathrm{C}$, with an intensifying screen.

Chromosomal locations of RGAs in maize were mainly obtained with 54 lines from the Tx303 × CO159 University of Missouri-Columbia immortalized $\mathrm{F}_{2}$ family (Gardiner et al. 1993). Other general mapping populations used were the T232 $\times$ CM37 and CO159 × Tx303 Brookhaven National Laboratory recombinant inbred families consisting of 48 and 41 individuals, respectively (Burr and Burr 1991), and the H99 ×
Mo17 recombinant inbred population of 70 individuals developed by Mike Lee (Iowa State University). To find RFLPs suitable for mapping, RGAs were used to probe DNA of the parental lines cut separately with up to 16 restriction enzymes. RFLP marker data previously obtained for the mapping populations were downloaded from the Maize Genome Database on the Internet. Mapping was performed with the computer program MAPMAKER Version II for Macintosh (Lander et al. 1987).

Populations segregating for the $r p 1, r p 3$, and $r p 4$ loci for resistance to maize common rust were used to estimate genetic linkage between these resistance loci and closely linked RGA loci. To construct the $r p 4$ mapping population, individuals from an $\mathrm{F}_{2}$ population segregating for the Rp4-A allele were infected with rust biotype $\mathrm{R} 1$, which is avirulent on plants containing $R p 4-A$. The 65 individuals that were susceptible and therefore homozygous for the susceptibility allele at rp4 were chosen for analysis. The rpl mapping population was derived from an $\mathrm{F}_{2}$ family of a cross between parents homozygous for either the Rpl-D or the Rpl-M allele of the $r p 1$ locus. The rust biotype $\mathrm{R} 1$, which is avirulent on $R p 1-D$ plants, was used to inoculate $100 \mathrm{~F}_{2}$ plants from this family, and rust biotype $\mathrm{R} 2$, which is avirulent on $R p 1-M$ plants, was used to inoculate another 100 individuals. In this way, 20 individuals homozygous for $R p 1-M$ (susceptible to biotype R1) and 18 individuals homozygous for $R p l-D$ (susceptible to biotype R2) were identified for use in mapping. Three backcross populations were used for mapping RGAs with respect to $r p 3$. The first consisted of 50 individuals from a backcross family segregating for $R p 3-D$, which was inoculated with rust biotype IN1 to determine which individuals carried the Rp3-D allele. Two additional backcross families were constructed that segregated for the $R p 3-A$ allele and either of two linked morphological markers. One of these was constructed by crossing an Rp3-A line to a line carrying the $r p 3$ (rust susceptible) allele and a recessive allele at the $y s 3$ (yellow stripe) locus and backcrossing the $\mathrm{F}_{1}$ to the $r p 3, y s 3$ parent. Recombinants were then selected between $R p 3-A$ and $y s 3$ with rust biotype IN1. The other backcross family was similar but was segregating for $R p 3-A$ and $g l 6$ (glossy $\underline{6}$ ).

To test the hypothesis that the RGA probe PIC20 identifies a resistance gene family at the $r p l$ locus, the probe was used in the Southern analysis of three mutants of the $R p 1-D$ allele believed to be the result of unequal crossing over events: $R p 1$ $D^{*-1}$, Rpl-D*-4, and Rpl-D*-24 (Pryor 1993).

\section{ACKNOWLEDGMENTS}

We thank Val Ryle and Judy Cassells for their excellent technical assistance. We are also grateful to Mike Lee, Ben Burr, and the Maize Genetics Cooperation Stock Centre for kindly providing maize immortalized $\mathrm{F}_{2}$ and recombinant inbred RFLP mapping populations, and to Theresa Musket for supplying RFLP clones. Thanks also go to Richard Michelmore of the University of California, Davis, for sharing primer sequences prior to their publication. N. C. was fully supported by the Grains Research and Development Corporation, Australia (project CSP197).

\section{LITERATURE CITED}

Aarts, M. G. M., te Lintel Hekkert, B., Holub, E. B., Beynon, J. L., Stiekema, W. J., and Pereira, A. 1998. Identification of R-gene homologous DNA fragments genetically linked to disease resistance loci 
in Arabidopsis thaliana. Mol. Plant-Microbe Interact. 11:251-258.

Anderson, P. A., Lawrence, G. J., Morrish, B. C., Ayliffe, M. A., Finnegan, E. J., and Ellis, J. G. 1997. Inactivation of the flax rust resistance gene $M$ associated with loss of a repeated unit within the leucine-rich repeat coding region. Plant Cell 9:641-651.

Bent, A. F., Kunkel, B. N., Dahlbeck, D., Brown, K. L., Schmidt, R., Giraudat, J., Leung, J., and Staskawicz, B. J. 1994. RPS2 of Arabidopsis thaliana: A leucine-rich repeat class of plant disease resistance genes. Science 265:1856-1860.

Bentolila, S., Guitton, C., Bouvet, N., Sailland, A., Nykaza, S., and Freyssinet, G. 1991. Identification of an RFLP marker tightly linked to the $H t 1$ gene in maize. Theor. Appl. Genet. 82:393-398.

Burr, B., and Burr, F. A. 1991. Recombinant inbreds for molecular mapping in maize: Theoretical and practical considerations. Trends Genet. 7:55-60.

Chourey, P. S., and Zurawski, D. B. 1981. Callus formation from protoplasts of a maize cell culture. Theor. Appl. Genet. 59:341-344.

Coe, E., Davis, G., McMullen, M., Musket, T., and Polacco, M. 1995. RFLP and genetic maps. Maize Genet. Coop. Newsl. 69:191-256.

Coe, E. H., Jr., and Neuffer, M. G. 1977. The genetics of corn. Pages 111-223 in: Corn and Corn Improvement. G. F. Sprague, ed. American Society of Agronomy, Madison, WI.

Devereux, J., Haeberli, P., and Smithies, O. 1984. A comprehensive set of sequence analysis programs for the VAX. Nucleic Acids Res. 12: 387-395.

Dixon, M. S., Jones, D. A., Keddie, J. S., Thomas, C. M., Harrison, K., and Jones, J. D. G. 1996. The tomato $C f-2$ disease resistance locus comprises two functional genes encoding leucine-rich repeat proteins. Cell 84:451-459.

Feinberg, A. P., and Vogelstein, B. 1983. A technique for radiolabeling DNA restriction endonuclease fragments to high specific activity. Anal. Biochem. 132:6-13.

Gardiner, J. M., Coe, E. H., Melia-Hankock, S., Hoisington, D. A., and Chao, S. 1993. Development of a core RFLP map in maize using an immortalized- $F_{2}$ population. Genetics 134:917-930.

Gish, W., and States, D. J. 1993. Identification of protein coding regions by database similarity search. Nat. Genet. 3:266-272.

Grant, M. R., Godiard, L., Straube, E., Ashfield, T., Lewald, J., Sattler, A., Innes, R. W., and Dangl, J. L. 1995. Structure of the Arabidopsis $R P M 1$ gene enabling dual specificity disease resistance. Science 269 : 843-846.

Hooker, A. L. 1985. Corn and sorghum rusts. Pages 207-236 in: The cereal rusts. Vol. II. Diseases, Distribution, Epidemiology, and Control. A. P. Roelfs and W. R. Bushnell, eds. Academic Press, Orlando, FL.

Hooker, A. L., and Saxena, K. M. S. 1971. Genetics of disease resistance in plants. Annu. Rev. Genet. 5:407-424.

Hulbert, S. H., and Bennetzen, J. L. 1991. Recombination at the RpI locus of maize. Mol. Gen. Genet. 226:377-382.

Johal, G., and Briggs, S. P. 1990. Placement of $h m l$ on the Pioneer RFLP map. Maize Genet. Coop. Newsl. 64:37.

Johal, G. S., and Briggs, S. P. 1992. Reductase activity encoded by the HM1 disease resistance gene in maize. Science 258:985-987.

Jones, D. A., Thomas, C. M., Hammond-Kosack, K. E., Balint-Kurti, P. J., and Jones, J. D. G. 1994. Isolation of the tomato $C f-9$ gene for resistance to Cladosporium fulvum by transposon tagging. Science 266: 789-793.

Jung, M., Weldekidan, T., Schaff, D., Paterson, A., Tingey, S., and Hawk, J. 1994. Generation-means analysis and quantitative trait locus mapping of anthracnose stalk rot genes in maize. Theor. Appl. Genet. 89:413-418.

Kanazin, V., Marek, L. F., and Shoemaker, R. C. 1996. Resistance gene analogs are conserved and clustered in soybean. Proc. Natl. Acad. Sci. USA 93:11746-11750.

Kyetere, D., Ming, R., McMullen, M., Pratt, R., Brewbaker, J., Musket, T., Pixley, K., and Moon, H. 1995. Monogenic tolerance to maize streak virus maps to the short arm of chromosome 1. Maize Genet. Coop. Newsl. 69:136-137.

Lagudah, E. S., Moullet, O., and Appels, R. 1997. Map-based cloning of a gene sequence encoding a nucleotide-binding domain and a leucinerich region at the $\mathrm{Cre} 3$ nematode resistance locus of wheat. Genome 40:659-665.

Lander, E. S., Green, P., Abrahamson, J., Barlow, A., Daly, M. J., Lincoln, S. E., and Newberg, L. 1987. MAPMAKER: An interactive computer package for constructing primary genetic linkage maps of experimental and natural populations. Genomics 1:174-181.

Lawrence, G. J., Finnegan, E. J., Ayliffe, M. A., and Ellis, J. G. 1995. The $L 6$ gene for flax rust resistance is related to the Arabidopsis bacterial resistance gene RPS2 and the tobacco viral resistance gene $N$. Plant Cell 7:1195-1206.

Leister, D., Ballvora, A., Salamini, F., and Gebhart, C. 1996. A PCRbased approach for isolating pathogen resistance genes from potato with potential for wide application in plants. Nat. Genet. 14:421-429.

Leister, D., Kurth, J., Laurie, D. A., Yano, M., Sasaki, T., Devos, K., Graner, A., and Schulze-Lefert, P. 1998. Rapid reorganization of resistance gene homologues in cereal genomes. Proc. Natl. Acad. Sci. USA 95:370-375.

Martin, G. B., Brommonschenkel, S. H., Chunwongse, J., Frary, A., Ganal, M. W., Spivey, R., Wu, T., Earle, E. D., and Tanksley, S. D. 1993. Map-based cloning of a protein kinase gene conferring disease resistance in tomato. Science 262:1432-1436.

McMullen, M. D., Jones, M. W., Simcox, K. D., and Louie, R. 1994. Three genetic loci control resistance to wheat streak mosaic virus in the maize inbred Pa405. Mol. Plant-Microbe Interact. 7:708-712.

McMullen, M. D., and Simcox, K. D. 1995. Genomic organization of disease and insect resistance genes in maize. Mol. Plant-Microbe Interact. 8:811-815.

Mindrinos, M., Katagiri, F., Yu, G.-L., and Ausubel, F. M. 1994. The A. thaliana disease resistance gene RPS2 encodes a protein containing a nucleotide-binding site and leucine-rich repeats. Cell 78:1089-1099.

Ming, R., Brewbaker, J. L., Pratt, R. C., Musket, T. A., and McMullen, M. D. 1997. Molecular mapping of a major gene conferring resistance to maize mosaic virus. Theor. Appl. Genet. 95:271-275.

Nelson, O. E., and Ullstrup, A. J. 1964. Resistance to leaf spot in maize: Genetic control of resistance to race 1 of Helminthosporium carbonum Ull. J. Hered. 55:195-199.

Ori, N., Eshed, Y., Paran, I., Presting, G., Aviv, D., Tanksley, S., Zamir, D., and Fluhr, R. 1997. The I2C family from the wilt disease resistance locus $I 2$ belongs to the nucleotide binding, leucine-rich repeat superfamily of plant resistance genes. Plant Cell 9:521-532.

Parker, J. E., Coleman, M. J., Szabò, V., Frost, L. N., Schmidt, R., van der Biezen, E. A., Moores, T., Dean, C., Daniels, M. J., and Jones, J. D. G. 1997. The Arabidopsis downy mildew resistance gene RPP5 shares similarity to the Toll and Interleukin-1 receptors with $N$ and $L 6$. Plant Cell 9:879-894.

Pryor, A. 1993. Transposon tagging of a rust resistance gene in maize Pages 469-476 in: Advances in Molecular Genetics of Plant-Microbe Interactions. Vol. 2. E. W. Nestler and D. P. S. Verma, eds. Kluwer Academic, Dordrecht, The Netherlands.

Saghai-Maroof, M. A., Soliman, K. M., Jorgensen, R. A., and Allard, R. W. 1984. Ribosomal DNA spacer-length polymorphism in barley: Mendelian inheritance, chromosomal location and population dynamics. Proc. Natl. Acad. Sci. USA 81:8014-8018.

Sambrook, J., Fritsch, E, F., and Maniatis, T. A. 1989. Molecular Cloning: A Laboratory Manual. 2nd ed. Cold Spring Harbor Laboratory, Cold Spring Harbor, NY

Sanz-Alferez, S., Richter, T. E., Hulbert, S. H., and Bennetzen, J. L. 1995. The Rp3 disease resistance gene of maize: Mapping and characterization of introgressed alleles. Theor. Appl. Genet. 91:25-32.

Saraste, M. Sibbald, P. R., and Wittinghofer, A. 1990. The P-loop - a common motif in ATP-and GTP-binding proteins. Trends. Biochem. Sci. 15:430-434.

Saxena, K. M. S., and Hooker, A. L. 1968. On the structure of a gene for disease resistance in maize. Proc. Natl. Acad. Sci. USA 61:1300-1305.

Seah, S., Sivasithamparam, K., Karakousis, A., and Lagudah, E. S. Cloning and characterisation of a family of disease resistance gene analogs from wheat and barley. Theor. Appl. Genet. (In press.)

Shen, K. A., Meyers, B. C., Islam-Faridi, M. N., Chin, D. B., Stelly, D. M., and Michelmore, R. W. (1998). Resistance gene candidates identified by PCR with degenerate oligonucleotide primers map to clusters of resistance gene in lettuce. Mol. Plant-Microbe Interact. 11:815-823.

Simcox, K. D., and Bennetzen, J. L. 1993. The use of molecular markers to study Setosphaeria turcica resistance in maize. Phytopathology 83:1326-1330.

Simcox, K. D., McMullen, M. D., and Louie, R. 1995. Co-segregation of the maize dwarf mosaic virus resistance gene, $M d m l$, with the nucleolus organizer region in maize. Theor. Appl. Genet. 90:341-346.

Song, W.-Y. Wang, G.-L., Chen, L.-L., Kim, H.-S., Pi, L.-Y., Holsten, T., Gardner, J., Wang, B., Zhai, W.-X., Zhu, L.-H., Fauquet, C., and Ron- 
ald, P. 1995. A receptor kinase-like protein encoded by the rice disease resistance gene, $\mathrm{Xa}-21$. Science 270:1804-1806.

Sudupak, M. A., Bennetzen, J. L., and Hulbert, S. H. 1993. Unequal exchange and meiotic instability of disease-resistance genes in the Rp1 region of maize. Genetics 133:119-125.

Traut, T. W. 1994. The functions and consensus motifs of nine types of peptide segments that form different types of nucleotide-binding sites. Eur. J. Biochem. 222:9-19.

Ullstrup, A. J. 1965. Inheritance and linkage of a gene determining resistance in maize to an American race of Puccinia polysora. Phytopathology 55:425-428.

Whitham, S., Dinesh-Kumar, S. P., Choi, D., Hehl, R., Corr, C., and Baker, B. 1994. The product of the tobacco mosaic virus resistance gene N; Similarity to Toll and the interleukin-1 receptor. Cell 78: 1101-1115.

Wilkinson, D. R., and Hooker, A. L. 1968. Genetics of reaction to Puc- cinia sorghi in ten corn inbred lines from Africa and Europe. Phytopathology 58:605-608

Yoshimura, S., Yamanouchi, U., Katayose, Y., Toki, S., Wang, Z.-X., Kono, I., Kurata, N., Yano, M., Iwata, N., and Sasaki, T. 1998. Expression of $X a 1$, a bacterial blight-resistance gene in rice, is induced by bacterial inoculation. Proc. Natl. Acad. Sci. USA 95:1663-1668.

Yu, Y. G., Buss, G. R., and Saghai Maroof, M. A. 1996. Isolation of a superfamily of candidate disease-resistance genes from soybean based on a conserved nucleotide-binding site. Proc. Natl. Acad. Sci. USA 93:11751-11756.

Zaitlin, D., DeMars, S. J., and Gupta, M. 1992. Linkage of a second gene for NCLB resistance to molecular markers in maize. Maize Genet. Coop. Newsl. 66:69-70.

Zaitlin, D., DeMars, S., and Ma, Y. 1993. Linkage of $r h m$, a recessive gene for resistance to southern corn leaf blight, to RFLP marker loci in maize (Zea mays) seedlings. Genome 36:555-564. 